\title{
The Construction Strategies of College Teachers' Multimodal Electronic Teaching Portfolio
}

\author{
Dong-yan $\mathrm{Li}^{1,}$, , Qing-feng Guo 2,b \\ ${ }^{1}$ College of Humanities and Social Sciences, Hei Longjiang Bayi Agricultural University, Daqing, Hei \\ Longjiang, China, 163319; \\ ${ }^{2}$ College of Information Technology and Sciences, Hei Longjiang Bayi Agricultural University, \\ Daqing, Hei Longjiang, China, 163319; \\ aredsun_2002@163.com, bgqfafg@126.com
}

\begin{abstract}
Keywords:college teachers, electronic teaching portfolio, multimodal discourse, meaning construction, network platform

Abstract. The paper mainly discusses college teachers' application of multimodal electronic teaching portfolio in light of theoretical basis and platform construction strategy and comes to the conclusion that electronic teaching portfolio under the network environment not only serves as the effective tool of teachers' professional growth, but also shows the important carrier of teacher's education teaching idea, which creates good multimodal language learning environment and conditions, and improves learners' learning enthusiasm and efficiency.
\end{abstract}

\section{Introduction}

The construction of electronic teaching portfolio is inseparable with the advanced information technology and network environment; in other words, the latter can offer strong physical support and guarantee for the former. More importantly, the progress of modern network and information technology makes feasible the present multimedia teaching information and teachers' providing students with multimodal discourse or set of words, images, sounds and movements, and other semiotic symbols, which can inspire students actively construct meaning. Therefore, under the present social and cultural background, the paper has conducted the feasibility analysis of college teachers' multimodal electronic teaching portfolio construction strategies within the framework of theoretical basis and construction strategies, which is in detailed analysis as follows.

\section{The theoretical basis of multimodal electronic teaching portfolio}

\section{The theory of multimodal discourse analysis}

It is generally believed that "multimodal discourse refers to the communication phenomenon by using hearing, sight, touch, and so many kinds of feeling and various means such as language, image, sound, movement and symbolic resources."[1] Its theoretical basis mainly comes from conceptual function, interpersonal function and textual function, namely, the three meta-functions put forward by professor Halliday.

Conceptual function refers to the fact that language is one of the things that exist in the subjective and objective world and reflect the process; interpersonal function refers to the fact that language is a means of doing things and meaningful activities used in society between people, which is bound to reflect the relationship between human beings; textual function refers to the fact that language users integrate conceptual function and interpersonal function in an organized way to form a text and realize the role of the meta-functions. Multimodal discourse holds the idea that the other symbols other than language are also the source of meaning systemically, which possess conceptual function, interpersonal function and textual function. Multimodal symbols apart from language are no longer just a form of communication, but a means to express meaning, which is considered to be in tradition paralanguage such as images, music, color and other visual symbols, as are increasingly standing in a prominent position. In other words, the analysis of the linguistic features needs special emphasis on the synthetic 
meaning of multimodal semiotics like image, sound, color and movement through the channels of visual, auditory, and behavioral symbols in discourse.

In fact, when they carry out multimodal electronic teaching portfolio practice, college teachers are able to set the space layout, color, multimedia courseware, audio, video, and other symbols resources as an organic whole, sharing the enormous effect of modern science and technology in the teaching media.

\section{The theory of social constructivism learning}

Social constructivism learning focuses on the social culture of learning and knowledge construction mechanism and thinks knowledge is actively constructed by an individual, but the construction is not random construction. It is influenced by the social and cultural factors and need to consult with others to achieve consistent meaning and constantly adjust and correct. Learning is to realize the significance of the construction process under the background of certain social culture through interpersonal coordination interaction, including four elements, i.e. "situation", "collaboration", "conversation" and "meaning construction" is the fourth factor [2].

In constructivism learning environment, teaching design should consider the teaching goal and situation creating that benefit students to construct meaning. Multimodal electronic teaching portfolio based on network can create the interface with the intuitive image and interactive learning environment, which is rich in resources, illustrated, beyond time and space, interactive and effective, stimulating learners' multiple senses together to build the meaning of discourse concomitantly. To cultivate the creative thinking ability of excellent college students, college teachers might as well employ multimodal electronic teaching portfolio to teach under the guidance of social constructionism learning theory.

Therefore, the two aspects, namely, multimodal discourse and social constructivism learning are utilized for the construction of multimodal electronic teaching portfolio platform.

\section{The platform construction strategies of multimodal electronic teaching portfolio}

Under the network environment the content of multimodal electronic teaching portfolio presents as multimodal presentation comprising the forms of audio, video, images, text, color, space layout, which can meet the social demand for the cultivation of comprehensive development-oriented talent and should get more attention and further development in the field of higher education. Because of this, multimodal electronic teaching portfolio platform construction strategies are discussed and analyzed, which are mainly reflected in the following respects.

\section{Choose the high quality network teaching platform}

According to the course or subject teaching target and characteristics, college teachers can use network education platform such as Moodle, WebCT or Blackboard to design scientifically and reasonably teaching content, helping learners understand and master the basic theory knowledge and the integrated use of knowledge to discover, analyze and solve problems. Moodle (Modular Object Oriented Dynamic Learning Environment) is free open source software, widely used in many countries of curriculum management system, developed by the Australian teacher Martin Dougiamas based on constructivism education theory; its significant characteristic is based on social constructivism teaching method to do its design; educators (teachers) and learners (students) are equal; in the teaching activities, they work together and jointly construct knowledge according to the existing experience. To use the software, learners aren't necessarily an expert in computer skill and it is enough to master the basic operation computers and the use of IE browser, college teachers can apply multimodal electronic portfolio to construct a good platform for teaching practice.

Blackboard is the digital teaching platform developed by the Blackboard company in the United States based on course as the center under the integrated "teaching" -"learning" network environment; teachers and students can be in multimedia and network platform for the communication of a variety of courses; teachers may develop on the platform network courses whereas learners can choose to study courses and course content and study independently. Ideas between learner-learner and teacher-learner 
can be discussed and communicated according to the needs of teaching and learning. WebCT (Web Course Tools) is asynchronous transmission and management system, developed by the British Columbia of Canadian department of computer science for Course of Development in colleges, including a series of powerful learning Tools automatically and tightly integrated with curriculum content, which can be used to develop complete online Course and the existing curriculum content can be published on the Internet. WebCT has strong interactivity between teacher-student and student-student, one of its marked characteristics is to provide a rich template and the guide mechanism for the teachers who don't understand programming teacher.

In contrast, BlackBoard and WebCT are commercial and the prices are expensive, so only a part of schools use them at home; free Moodle platform is used in some schools where money is not adequate. College teachers should consider how to further deepen and use the existing teaching platform through the multimodal discourse analysis and the social constructivism learning theory by building a course module with a view to achieving the goal of teaching theory and teaching efficiency.

\section{Make clear the basics of multimodal electronic teaching portfolio}

Teaching portfolio is comprehensive powerful evidence which is involved in the whole process of cultivating learners regarding teaching goal, teaching materials, class information extraction and teachers' teaching reflection, teacher's teaching and scientific research achievements in the teaching of sustainability information and teachers' performance evaluation [3].

The basic elements include: the first is a teacher's explanation of teaching idea, teaching goal and teaching plan; the second is teachers' design and development of multimedia multimodal teaching materials through the Internet, pictures, video, and other social symbolic resources which can fully arouse learners' various senses such as vision, hearing, touch to construct discourse meaning and provide relatively real communicative context for learners; the third is to assess students' learning objectives and outcomes, such as evaluation methods used in the list and feedback to students to evaluate the results of sample, students' assignments samples, student learning and work pictures, audio, video, etc.; the fourth is teachers' continuous self-evaluation, self-reflection, self-renewal, helping to find whether their efforts have for the students created a good learning environment or not, whether or not promoted the students to learn and achieve the teaching goal, whether or not raised its own teaching ability; the fifth is that college teachers should constantly reserve specialized knowledge, expand the scope, make connections, possess basic research capacity and facilitate teaching and scientific research accumulation. As is known to all, a person's academic level can decide what lessons he teaches; a person's teaching level can decide what lessons he teaches well. Clearly, teachers' research ability and teaching ability coexist and co-prosper, which can promote each other.

So college teachers' teaching portfolio is not only the information collecting container, but teachers' experience sharing and ideas exchanging media platform with others also. More importantly, it is systematic engineering through reflection and construction, becoming rich through cooperation and finally promoting the goal of professional development for teachers and students' learning progress.

\section{Construct multimodal electronic portfolio platform strategically}

One of the important characteristics of network platform is based on social constructivism teaching thoughts, allowing multiple subjects to co-construct and share dynamic teaching environment between teachers and teachers, teachers and students or students and students to collaborate and to construct knowledge according to their original experience. Based on the following three main modules, multimodal electronic portfolio platform is constructed.

The first two multimodal modules mainly include teaching content module and interaction module. In the teaching content module, teachers who teach the same course can collaboratively design courses, for instance, set suitable platform interface color, font size, layout and other things available, expound the teaching idea, teaching plan and present multimodal social symbolic resources such as audio, video, images and the like as teaching resources, so that the students can see in their own login screen the multimodal learning resources teachers have constructed. In interaction module, teachers and students can establish a discussion board, learning-group, virtual classroom for communication and interaction 
according to different demands. When they raise some problems or a specific topic for discussion, learners will get the feedback in time; indeed, every interaction module needs to encourage students to actively participate in it. So, it is often through communication and interaction that students and teachers can maintain some degree of care about each other and understanding, which can make learners continue to learn and acquire new learning experience and satisfaction and thus form a sense of belonging to the whole network learning space and social emotional connection, gradually playing a positive role in promoting their learning.

In addition, the key of the network platform design concerning multimodal portfolio is evaluation and reflection. The evaluation and reflection module mainly and dynamically display students' and teachers' progress, achievement and learning situation through independence or cooperation, which is embodied in a specific period in the completion of the prescribed objectives based on a series of material and inference. Teachers can realize the diversified evaluation such as student's typical assignment, test, and paper, which should reflect teaching motivation, diagnosis, and promotion and weaken the evaluation of selection and discrimination with teachers playing a leading role in the evaluation, paying attention to student's individual difference and encouraging student's creativity.

\section{Conclusion}

The paper mainly discussed college teachers' application of multimodal electronic teaching portfolio in light of theoretical basis and platform construction strategy and came to the conclusion that electronic teaching portfolio under the network environment not only serves as the effective tool of teachers' professional growth, but also shows the important carrier of teacher's education teaching idea, which creates good multimodal language learning environment and conditions, and improves learners' learning enthusiasm and efficiency. In other words, the conclusion is drawn that multimodal electronic teaching portfolio based on network can arouse the enthusiasm of teachers' effective teaching and learners' effective learning at once without being limited by space and time, providing colorful multimedia multimodal resources for learners and helping to promote the growth of university teachers and learners.

\section{Acknowledgements}

This work was financially supported by the Heilongjiang Social Science Foundation (14D016), Heilongjiang Provincial Education Ecience Foundaton (GBD1212056) and Heilongjiang Agricultural Reclamation Bureau Foundation (HNK12A - 14-11).

\section{References}

[1] De-lu zhang. Multimodal discourse theory and the application of media technology in foreign language teaching [J]. Foreign language teaching, vol. 4 (2009), p15-20.

[2] Dong-hui zheng. Social constructivism learning papers review [J]. Journal of Ningbo university (education sciences), vol. 6 (2004), p35-38.

[3] Li jing. China undergraduate research-oriented teaching and its application of portfolio evaluation [D]. Harbin institute of technology (2011), p13-42.

\section{Author Introduction}

The first author: Dong-yan li, 1978, female, lecturer; major study field: foreign language teaching and multimodal discourse, e-mail: redsun_2002@163.com. 
Corresponding author: Qing-feng guo, 1976, male, lecturer; major field: computer science and technology, e-mail: gqfdfg@126.com. 